\title{
Evaluasi Kebijakan Pengadaan Kebutuhan Mesin Kapal (Studi Kasus PT Pertamina Region VI Balikpapan)
}

\author{
Wagimin \\ Staf Pengajar Jurusan Teknik Mesin \\ Fakultas Teknologi Industri Universitas Balikpapan \\ Jl. Pupuk Raya Balikpapan Kalimantan Timur \\ Email : wagimin_stikom@ymail.com
}

\begin{abstract}
PT. Pertamina (Persero) Region VI Balikpapan Kalimantan Marine Department is responsible for the smooth distribution of oil at sea, After about six years of operation to replace the engines were new, there are possible factors that influence the course of a new boat engine replacement project due to different the current situation with situation at the time to do feasibility study six years earlier, so that should be evaluated to determine whether the project is still feasible to run. The financial aspects of the old boat engine repair NPV\$482,006 while for a new boat engine replacement \$1,201,148 NPV and boat contrac \$.1.069.480. IRR value is greater than that required by the company, which is to repair the old boat engines for the replacement of $33.2 \%$ while the new boat engine replacement 38, 67\% improvement in PI and old ship engines for 1,09 while for new ship engines 1,03 replacement so that the investment is feasible, Payback Period for the old boat engine repair over 3 years, 10 months, 2 days while a replacement engine for a new 3 year and 5 ships month 19 days. From the sensitivity analysis found that the project to repair the old boat engine feasible if cashflow is greater than \$.281.615 while for a new boat engine replacement is feasible if cash flow is greater than \$ 541.538. Of the three alternative NPV feasible because alternative investments are Mutually Exclusive then only have one alternative calculation that is an alternative to the second purchase of new ship's engines.
\end{abstract}

Keyword: Investment Mutually Exclusive, Aspect financial: NPV, IRR, Profitability Index, Payback period and Sensitivity.

\begin{abstract}
Abstraksi
PT. Pertamina (Persero) Region VI Balikpapan Kalimantan Marine Departement adalah bertanggung jawab terhadap kelancaran distribusi minyak di laut, Setelah kurang lebih enam tahun beroperasi mengganti mesin kapal baru, dimungkinkan terdapat faktor-faktor yang berpengaruh terhadap jalannya proyek penggantian mesin kapal baru karena berbedanya situasi saat ini dengan situasi pada saat dilakukan studi kelayakan enam tahun sebelumnya, sehingga perlu dilakukan evaluasi untuk mengetahui apakah proyek tersebut masih layak untuk dijalankan. Aspek financial perbaikan mesin kapal lama diperoleh NPV \$482.006 sedangkan untuk penggantian mesin kapal baru NPV \$1.201.148 dan NPV kontrak kapal adalah \$.1.069.480. nilai IRR lebih besar dari yang disyaratkan perusahaan, yaitu untuk perbaikan mesin kapal lama 33,2\% sedangkan untuk penggantian mesin kapal baru 38,67 \% dan nilai PI perbaikan mesin kapal lama sebesar 1.09 sedangkan untuk penggantian mesin kapal baru 1,03 sehingga investasi dikatakan layak, Payback Period untuk perbaikan mesin kapal lama lebih 3 tahun, 10 bulan, 2 hari sedangkan untuk penggantian mesin kapal baru 3 tahun 5 bulan 19 hari. Dari analisis sensitivitas diketahui bahwa proyek untuk perbaikan mesin kapal lama layak jika aliran kas lebih besar dari \$.281.615 sedangkan untuk penggantian mesin kapal baru masih layak untuk dilakukan jika aliran kas lebih besar dari \$ 541.538.Dari NPV ketiga alternative layak dilakukan karena alternative investasi bersifat Mutually Exclusive maka hanya dipilih satu alternatif perhitungan yaitu alternatif ke II pembelian mesin kapal baru.
\end{abstract}

Kata Kunci : Investasi Mutually Exclusive, Aspek finansial: NPV, IRR, Profitability Index, Payback period dan Sensitifitas. 


\section{Pendahuluan}

PT Pertamina Marine Region VI Balikpapan memiliki Armada Kapal Ringan dan Kapal Barang (KRKB) seperti Tug Boat, Landing Craft, Passenger Line, Mooring Boat Water Bus serta Cank water jumlah 18 buah kapal, keseluruhan kapal dan mesin kapal yang ada saat ini berusia rata rata 30 tahun.

Mesin kapal saat ini banyak spare part tidak di produksi lagi, sehingga hambatan/kendala jika dilakukan perbaikan Top maupun perbaikan General Over haul akan menghambat operasional pelaksanaan pekerjaan di lapangan. Pemilihan kebijakan perusahaan pengadaan kapal ada tiga pilihan pertama memperbaiki mesin kapal, kedua mengganti mesin kapal baru dan ketiga menyewa kapal secara keseluruhan. Menentukan kebijakan untuk memenuhi kebutuhan kapal dengan memperbaiki mesin kapal lama, penggantian mesin kapal baru atau kontrak kapal dengan pemilihan Investasi yang bersifat Mutually Exclusif.Menentukan tingkat sensitifitas pengaruh dari perubahan pendapatan terhadap kebijakan yang dipilih.

\section{Kajian Pustaka}

\subsection{Analisis Kelayakan}

Kelayakan pada suatu kegiatan adalah mengkaji kelayakan suatu gagasan yang dikaitkan dengan kemungkinan tingkat keberhasilan tujuan yang hendak dicapai.

\subsection{Aspek Pasar dan Pemasaran}

Aspek pasar menempati urutan pertama dalam studi kelayakan proyek. Adapun tujuan aspek ini adalah untuk mengetahui berapa besar permintaan produk serta kecenderungan perkembangan perkembangan permintaan selama masa kehidupan proyek yang akan datang secara cermat.

\subsection{Peramalan}

Peramalan diperlukan untuk menetapkan kapan suatu peristiwa akan terjadi atau timbul sehingga tindakan yang tepat dapat dilakukan. Perencanaan merupakan kebutuhan yang besar, karena untuk pengambilan keputusan. Peramalan merupakan alat bantu yang penting dalam perencanaan yang efektif dan efisien. Peramalan berperan dibeberapa bagian dalam organisasi (Assauri, 1984) antara lain: (1) Menentukan kebutuhan sumber daya yang diperlukan; (2) Penambahan sumber daya ; dan (3) Penjadwalan sumber daya yang ada.

\subsection{Teknik-teknik peramalan}

Metode-metode peramalan yaitu sebagai berikut :

\section{a.Simple Average (rerata sederhana)}

Metode simple average menggunakan sejumlah data aktual dari periode-periode sebelumnya yang kemudian dihitung rataratanya untuk meramalkan periode waktu berikutnya. Metode rata-rata secara sederhana menghitung rata-rata dari data yang tersedia (sejumlah $\mathrm{t}$ ).

\section{b.Simple moving average}

Metode ini menggunakan satu set data dengan jumlah data yang tetap, sesuai perode pergerakannya (moving period), kemudian nilai rata-rata dari set data tersebut digunakan untuk meramalkan nilai periode berikutnya. Dengan munculnya data yang baru, maka nilai rata-rata yang baru dapat dihitung dengan yang terbaru.

\subsection{Depresiasi}

Depresiasi (penyusutan) pada dasarnya adalah penurunan nilai suatu properti atau aset karena waktu dan pemakaian. 
Dalam metode ini di anggap nilai benda modal berkurang secara tetap.

2.6 MARR (Minimum Attractive rate of Return)

Minimum Atractive Rate of Return adalah tingkat bunga yang dipakai sebagai patokan dasar oleh perusahaan dalam mengevaluasi dan membandingkan berbagai alternatif. MARR ini adalah nilai minimal dari tingkat pengembalian atau bunga yang diterima dari investor. Dengan kata lain bila suatu investasi menghasilkan tingkat pengembalian atau bunga yang lebih kecil dari MARR maka investasi dinilai tidak ekonomis sehingga tidak layak untuk dikerjakan

\subsection{Mendefinisikan Alternatif Investasi}

Dalam fase ini sangat menentukan apakah proses pengambilan keputusan akan bisa kearah yang optimal atau tidak, dimana penentuan alternatif investasi adalah fase yang sangat teknis.

Ada 3 jenis alternatif yang akan dibahas disini berkaitan dengan proses penentuan alternatif, yaitu alterntifalternatif yang independent, alternatifalternatif "mutually exclusive" dan alternatif-alternatif yang bersifat tergantung / contigen (Pujawan I N, 1995).

a. Alternatif - Alternatif Independent

b. Alternatif - Alternatif Bersifat Mutually Exclusive

c. Alternatif - Alternatif yang Contigent

\subsubsection{Analisis Nilai Sekarang (Net Present Value Analysis)}

Net present Value adalah selisih antara present value dari investasi dengan nilai sekatang dari penerimaan-penerimaan kas bersih (aliran kas operasional maupun aliran kas terminal) dimasa yang akan datang.

Rumus yang digunakan untuk menghitung NPV adalah : n

$$
\begin{gathered}
\mathrm{NPV}=-\mathrm{Ao}+\sum_{\ldots \ldots \ldots \ldots \ldots \ldots \ldots . .(2.1)} \underline{\mathrm{At}}+\underline{\mathrm{SV}} \\
\mathrm{t}=0(1+i)^{1} \quad(1+i)^{\mathrm{x}}
\end{gathered}
$$

Dimana : bunga)

$\mathrm{I}=$ Discount rate (tingkat

At $=$ Aliran kas pada periode $\mathrm{t}$

$\mathrm{X}=$ Periode aliran kas

Ao $=$ Investasi awal

$\mathrm{SV}=$ Nilai sisa

$\mathrm{n}=$ Waktu (tahun)

\subsubsection{Internal Rate of Return (IRR)}

Metode ini digunakan untuk mencari tingkat bunga yang menyamakan nilai sekarang dari arus kas yang diharapkan dimasa datang atau penerimaan kas, dengan pengeluaran investasi awal.

Rumus yang digunakan untuk menghitung IRR adalah :

$$
I R R=i_{1}+\frac{N P V_{1}}{\left(N P V_{1}-N P V_{2}\right)}\left(i_{2}-i_{1}\right) \ldots \ldots . .
$$

$\mathrm{IRR}=$ tingkat bunga yang dicari nilainya

$\mathrm{i}=$ tingkat discount rate yang menghasilkan $\mathrm{NPV}_{1}$

$\mathrm{i}_{2}=$ tingkat discount rate yang menghasilkan $\mathrm{NPV}_{2}$

Untuk memperoleh i yang memberikan nilai NPV $=0$ maka dilakukan dengan cara coba-coba (trial and error), yaitu dengan cara menginterpolasikan tingkat suku bunga yang satu dengan tingkat suku bunga yang lain

\subsubsection{Periode Payback (Payback Period)}

Periode Payback dari suatu investasi menggambarkan panjangnya waktu yang diperlukan agar dana yang ditanam pada suatu invesasi dapat kembali seluruhnya. Dengan formulasinya sebagai berikut : 


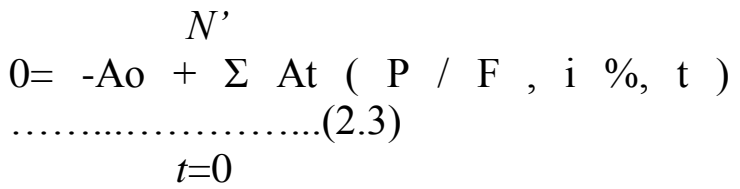

Dimana:

$$
\begin{aligned}
\text { At } & =\text { Aliran kas tahun ke-t } \\
\text { Ao } & =\text { 'Investasi awa } \\
\mathrm{t} & =\text { 'Tingkat suku bunga } \\
\mathrm{n} & =\text { Waktu (tahun) }
\end{aligned}
$$

Atau,

$$
\begin{aligned}
& \mathrm{PI} \\
& \underset{\text { Proceeds.............................. }}{\text { Net Investasi }}
\end{aligned}
$$

\subsubsection{Analisis Sensitivitas}

Analisis sensitivitas ini akan memberikan gambaran sejauh mana suatu keputusan akan cukup kuat berhadapan dengan perubahan faktor-faktor dan parameter yang berpengaruh. Analisis sensitivitas dilakukan dengan mengubah nilai dari suatu parameter pada suatu saat untuk selanjutnya dilihat bagaimana pengaruhnya terhadap akseptabilitas suatu alternatif investasi seperti ongkos investasi, aliran kas, tingkat bunga, nilai sisa, tingkat pajak dsb.

\section{Kas Bersih / Cash flow atau proceeds}

Cash flow atau proceeds (Alwi,1983) adalah earning after taxes plys depresiasi. Cara penilaian usulan investasi yaitu didasarkan pada aliran kas (cash flow) bukan keuntungan yang dilaporkan dalam buku. Karena untuk menghasilkan keuntungan tambahan, kita dapat mempunyai kas untuk ditanamkan kembali. Keuntungan yang dilaporkan dalam buku belum pasti dalam bentuk kas, sehingga dengan demikian jumlah kas yang ada dalam perusahaan belum tentu sama dengan jumlah keuntungan yang dilaporkan dalam buku. Setiap usulan pengeluaran modal (capital expenditure) selalu mengandung dua macam aliran kas (cash flow), yaitu :

1.Aliran kas keluar neto (net outflow of cash), yaitu yang diperlukan untuk investasi baru.

2.Aliran kas masuk netto tahuman (net annual inflow of cash), yaitu sebagai hasil dari investasi baru tersebut yang ini sering disebut net cash proceeds atau cukup dengan istilah proceeds

\section{Pembahasan}

Dari perhitunagan Kas Bersih Perbaikan Mesin Lama,pembelian mesin baru dan kontrak kapal Tahun 2016 - 2020 dapat

\begin{tabular}{|c|c|c|c|c|c|}
\hline & \multicolumn{5}{|c|}{ Tahun } \\
\hline & 2016 & 2017 & 2018 & 2019 & 2020 \\
\hline $\begin{array}{l}\text { Pendapatan } \\
\text { Penjualan Jasa }\end{array}$ & 969.158 & 984.788 & 1.005 .984 & 1.022 .327 & 1.036 .061 \\
\hline B. Langsung & 154.556 & 159.183 & 168.140 & 178.237 & 185.238 \\
\hline B. Tidak Langsung & 33.900 & 33.900 & 33.900 & 33.900 & 33.900 \\
\hline Laba Kotor & 780.702 & 791.705 & 803.944 & 810.190 & 816.923 \\
\hline Depresiasi & 84.660 & 84.660 & 84.660 & 84.660 & 84.660 \\
\hline EBT & 696.042 & 707.045 & 719.284 & 725.530 & 732.263 \\
\hline Pajak $(10 \%-30 \%)$ & 207.840 & 211.141 & 214.812 & 216.686 & 218.706 \\
\hline EAT & 488.201 & 495.903 & 504.471 & 508.843 & 513.556 \\
\hline Depresiasi & 84.660 & 84.660 & 84.660 & 84.660 & 84.660 \\
\hline Kas Bersih & 572.862 & 580.564 & 589.131 & 593.503 & 598.216 \\
\hline
\end{tabular}
terlihat pada table 3.1,3.2 dan tabel 3.3.

Tabel 3.1 Estimasi Aliran Kas Untuk Perbaikan Kapal Lama

\begin{tabular}{|l|c|c|c|c|}
\hline \multirow{2}{*}{} & \multicolumn{4}{|c|}{ Tahun } \\
\cline { 2 - 5 } & 2016 & 2017 & 2018 & 2019 \\
\hline Pendapatan & & & & \\
Penjualan Jasa & 539.084 & 563.972 & 590.689 & 607.816 \\
\hline B. Langsung & 126.101 & 137.525 & 149.985 & 163.574 \\
\hline B. Tidak Langsung & 32.900 & 32.900 & 32.900 & 32.900 \\
\hline Laba Kotor & 380.083 & 393.547 & 407.804 & 411.342 \\
\hline Depresiasi & 78.750 & 78.750 & 78.750 & 78.750 \\
\hline EBT & 301.333 & 314.797 & 329.054 & 332.592 \\
\hline Pajak (10\%-30\%) & 89.427 & 93.467 & 97.744 & 98.805 \\
\hline EAT & 211.906 & 221.330 & 231.310 & 233.787 \\
\hline Depresiasi & 78.750 & 78.750 & 78.750 & 78.750 \\
\hline Aliran Kas Bersih & 290.656 & 300.081 & 310.061 & 312.537 \\
\hline
\end{tabular}

Tabel 3.2 Estimasi Aliran Kas Untuk Pembelian Mesin Kapal Baru 
Tabel 3.3 Estimasi Aliran Kas untuk Kontrak Kapal Baru

\begin{tabular}{|c|c|c|c|c|c|}
\hline & \multicolumn{5}{|c|}{ Tahun } \\
\hline & 2016 & 2017 & 2018 & 2019 & 2020 \\
\hline \begin{tabular}{|l|} 
Pendapatan \\
Penjualan Jasa \\
\end{tabular} & 919.971 & 92.7011 & 942.487 & 949.413 & $951.67 \%$ \\
\hline B. Langsung & 125.101 & 127.525 & 139.985 & 143.574 & 143.99 \\
\hline B. Tidak Langsung & 33.900 & 33.900 & 33.900 & 33.900 & 33.9000 \\
\hline Laba Kotor & 760.970 & 765.586 & 768602 & 771.939 & $773.78 \%$ \\
\hline Depresiasi & 84.660 & 84.660 & 84.660 & 84.660 & 84.660 \\
\hline $\mathrm{EBT}$ & 676.310 & 680.926 & 683.942 & 687.279 & 689.123 \\
\hline $\operatorname{Pajak}(10 \%-30 \%)$ & 201.920 & 203.305 & 204.210 & 205.211 & 205.763 \\
\hline EAT & 474.389 & 477.620 & 479.732 & 482.068 & 483.35 \\
\hline Depresiasi & 84.660 & 84.660 & 84.660 & 84.660 & 84.660 \\
\hline Kas Bersih & 559.050 & 562.281 & 564.392 & 566.729 & $568.02 \mathrm{C}$ \\
\hline
\end{tabular}

Untuk mengetahui Perhitungan NPV

Perbaikan Mesin Kapal Lama dapat terlihat pada tabel 3.4

Tabel 3.4 Perhitungan NPV Perbaikan Mesin Kapal Lama

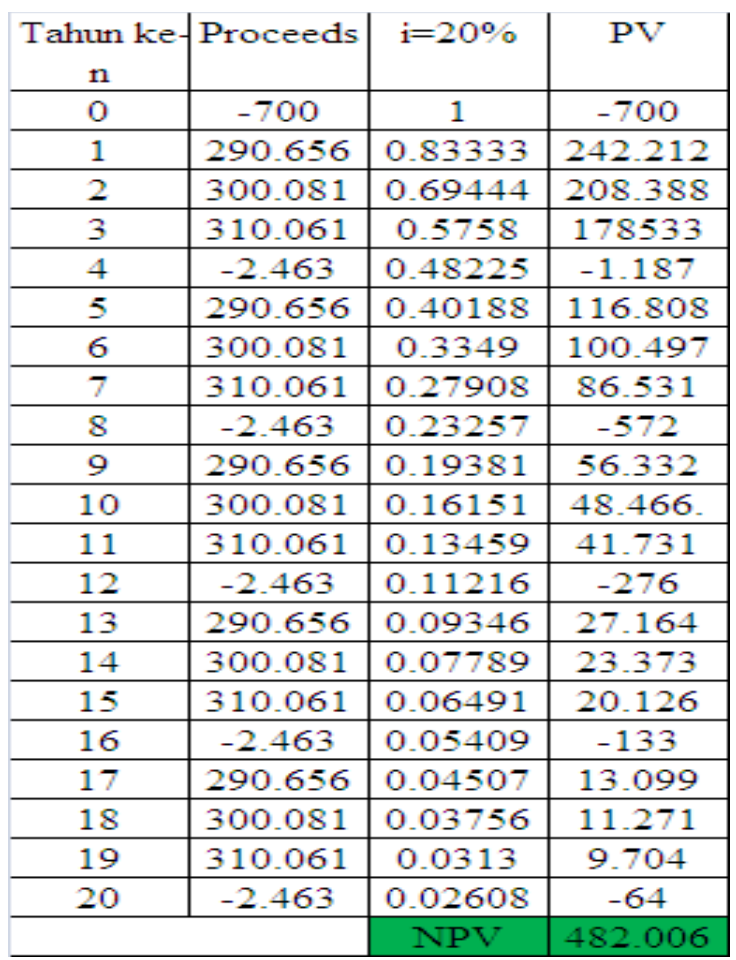

Perhitungan NPV Penggantian Mesin Kapal Baru dapat terlihat pada tabel 3.5

\begin{tabular}{|c|c|c|c|}
\hline $\begin{array}{c}\text { Tahun ke } \\
\mathrm{n}\end{array}$ & Proceeds & $\mathrm{i}=20 \%$ & PV \\
\hline 0 & -1.411 .000 & 1 & -1.411 .000 \\
\hline 1 & 559.05 & 0.83333 & 465.873 \\
\hline 2 & 562.281 & 0.69444 & 390.47 \\
\hline 3 & 564.392 & 0.5758 & 324.976 \\
\hline 4 & 566.729 & 0.48225 & 273.305 \\
\hline 5 & 568.02 & 0.40188 & 228.275 \\
\hline 6 & 572.862 & 0.3349 & 191.851 \\
\hline 7 & 580.564 & 0.27908 & 162.023 \\
\hline 8 & 589.131 & 0.23257 & 137.014 \\
\hline 9 & 593.503 & 0.19381 & 115.026 \\
\hline 10 & -248.384 & 0.16151 & -40.116 \\
\hline 11 & 559.05 & 0.13459 & 75.242 \\
\hline 12 & 562.281 & 0.11216 & 63.065 \\
\hline 13 & 564.392 & 0.09346 & 52.748 \\
\hline 14 & 566.729 & 0.07789 & 44.142 \\
\hline 15 & 568.02 & 0.06491 & 36.87 \\
\hline 16 & 572.862 & 0.05409 & 30.986 \\
\hline 17 & 580.564 & 0.04507 & 26.166 \\
\hline 18 & 589.131 & 0.03756 & 22.127 \\
\hline 19 & 593.503 & 0.0313 & 18.576 \\
\hline 20 & -248.384 & 0.02608 & -6.477 \\
\hline & & NPV & 1.201 .148 \\
\hline
\end{tabular}

Perhitungan NPV Kontrak Kapal dapat terlihat pada tabel 3.6

Tabel 3.6 Perhitungan NPV Kontrak Kapal

\begin{tabular}{|c|c|c|c|}
$\begin{array}{c}\text { Tahun ke } \\
\mathrm{n}\end{array}$ & Proceeds & $\mathrm{i}=20 \%$ & $\mathrm{PV}$ \\
\hline 1 & 254.371 & 0.83333 & 211.974 \\
\hline 2 & 240.005 & 0.69444 & 166.669 \\
\hline 3 & 232.887 & 0.5758 & 134.096 \\
\hline 4 & 217.813 & 0.48225 & 105.04 \\
\hline 5 & 198.079 & 0.40188 & 79.603 \\
\hline 6 & 193.558 & 0.3349 & 64.822 \\
\hline 7 & 187.188 & 0.27908 & 52.24 \\
\hline 8 & 186.384 & 0.23257 & 43.347 \\
\hline 9 & 180.727 & 0.19381 & 35.026 \\
\hline 10 & 172.461 & 0.16151 & 27.854 \\
\hline 11 & 254.371 & 0.13459 & 34.235 \\
\hline 12 & 240.005 & 0.11216 & 26.918 \\
\hline 13 & 232.887 & 0.09346 & 21.765 \\
\hline 14 & 217.813 & 0.07789 & 16.965 \\
\hline 15 & 198.079 & 0.06491 & 12.857 \\
\hline 16 & 193.558 & 0.05409 & 10.469 \\
\hline 17 & 187.188 & 0.04507 & 8.436 \\
\hline 18 & 186.384 & 0.03756 & 7 \\
\hline 19 & 180.727 & 0.0313 & 5.656 \\
\hline 20 & 172.461 & 0.02608 & 4.497 \\
\hline & & NPV & 1.069 .480 \\
\hline & & & \\
\hline
\end{tabular}




\section{Perbandingan Metode Analisis}

Dalam analisis sensitifitas dimasukan nilai investasi maka menghasilkan nilai NPV yang negatif dapat dikatakan tidak layak. Dimana pada analisis perhitungan bahwa Kontrak kapal tidak layak karena menghasilkan nilai NPV yang negatif. Adapun perhitungan Perbandingan Metode Analisis dapat terlihat pada tabel 3.7

Tabel 3.7 Perbandingan Metode Analisis

\begin{tabular}{|c|c|c|c|c|c|c|c|}
\hline \multirow[t]{2}{*}{ I } & \multirow[t]{2}{*}{$\begin{array}{l}\text { Metode } \\
\text { Analisis }\end{array}$} & \multicolumn{2}{|c|}{$\begin{array}{c}\text { Perbaikan mesin } \\
\text { Kapal Lama }\end{array}$} & \multicolumn{2}{|c|}{$\begin{array}{c}\text { Pembelian } \\
\text { Kapal Vesin Baru }\end{array}$} & \multicolumn{2}{|c|}{ Kontrak Kapal } \\
\hline & & Hasil & $\begin{array}{c}\text { Keteranga } \\
\text { n }\end{array}$ & Hasil & Keterangan & Hasil & $\begin{array}{c}\text { Keteranga } \\
\text { n }\end{array}$ \\
\hline 1 & SPY & 482.006 & Layak & 1.201 .1 & Layak & 1.069 .48 & Layak \\
\hline 2 & IRR & $33,2 \%$ & Layak & $\begin{array}{c}38,67 \\
\%\end{array}$ & Layak & $14,35 \%$ & $\begin{array}{l}\text { Tidak } \\
\text { layak }\end{array}$ \\
\hline 3 & PI & 1,09 & Layak & 1,03 & Layak & 1,01 & Layak \\
\hline 4 & $\begin{array}{l}\text { Pay } \\
\text { back } \\
\text { Period }\end{array}$ & $\begin{array}{c}3 \text { tahun } \\
10 \text { bulan } \\
2 \text { hari }\end{array}$ & Layak & $\begin{array}{c}3 \\
\text { tahun } \\
5 \text { bulan } \\
19 \text { hari }\end{array}$ & Layak & $\begin{array}{l}19 \\
\text { tahun, } 9 \\
\text { bulan, } 6 \\
\text { hari }\end{array}$ & $\begin{array}{l}\text { Tidak } \\
\text { layak }\end{array}$ \\
\hline 5 & $\begin{array}{l}\text { Analisis } \\
\text { Sensitivitas }\end{array}$ & $\$ .281 .615$ & $\begin{array}{c}\text { Layak } \\
\text { aliran kas } \\
>\$ .281 .615\end{array}$ & $\begin{array}{c} \\
541.53 \\
8\end{array}$ & $\begin{array}{c}\text { Layak aliran } \\
\text { kas> } \\
\text { S541.538 }\end{array}$ & .348164 & $\begin{array}{l}\text { Tidak } \\
\text { Layak }\end{array}$ \\
\hline
\end{tabular}

Metode yang digunakan untuk melakukan analisis kelayakan proyek pada penelitian ini adalah Aspek Pasar, Aspek Teknis Aspek Manajemen, Aspek Finansial dan Analisis Sensitivitas

\section{Kesimpulan}

1) Pemilhan alternatif yang bersifat Mutually Exclusif maka hanya dipilih satu altenatif yang dianggap terbaik menurut kreteria yang ditentukan.

2) dari alternatif dapat disimpulkan untuk mendapatkan hasil yang lebih menguntungkan dari umur ekonomis yang ditawarkan alternative I maka dipilih Alternatif II yaitu penggantian mesin kapal baru yang memiliki keuntungan lebih besar dibandingkan alternatif ke I dan alternatif III.

\section{Daftar Pustaka}

Ristono.A dan Puryani, 2010, Ekonomi Teknik, Graha Ilmu Yogyakarta

Soemadi Kusumaningrum , 2004,Model Penggantian Optimal Untuk mesin reparable Bergaransi Dengan Pemograman Dinamis, Disertasi Institut teknologi Bandung

Degarmo E, Sullivan G, 1997. Bontadelli A dan Elin M. Engineering Economy, tenth Edition. Jakarta

Husnan.S dan Suwarsono, 2000, Studi Kelayakan Proyek, UPP AMP YKPN Yogyakarta

Sutojo.S. 1993. Studi Kelayakan Proyek Teori \& Praktek. Jakarta: PT. Midas Surya Grapindo.

Sofyan Addauri, 1984, Teknik dan Metode Peramalan, Edisi Satu, LPFEUI

Soeharto, Iman, 2002. Studi Kelayakan Proyek. Jakarta : Erlangga

Suad Husnan, Suwarsono, 1999,Studi Kelayakan Proyek, UPP AMP YKPN Yogyakarta 